IRA-International Journal of Education \& Multidisciplinary Studies ISSN 2455-2526; Vol.06, Issue 01 (2017)

Pg. no. 1-8

Institute of Research Advances

http://research-advances.org/index.php/IJEMS

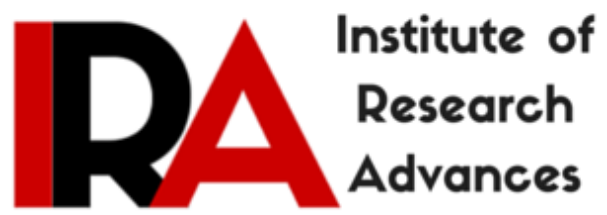

\title{
Promoting Self-Learning in Developing Communication Skills of Technical Students
}

Dr. M. Pratibha

Professor-English

Vidya Jyothi Institute of Technology, India.

Type of Review: Peer Reviewed.

DOI: http://dx.doi.org/10.21013/jems.v6.n1.p1

\section{How to cite this paper:}

Pratibha, M. (2017). Promoting Self-Learning in Developing Communication Skills of Technical Students. IRA International Journal of Education and Multidisciplinary Studies (ISSN 2455-2526), 6(1), 1-8. doi:http://dx.doi.org/10.21013/jems.v6.n1.p1

(C) Institute of Research Advances

\section{(cc) EY-NC}

This work is licensed under a Creative Commons Attribution-Non Commercial 4.0 International License subject to proper citation to the publication source of the work.

Disclaimer: The scholarly papers as reviewed and published by the Institute of Research Advances (IRA) are the views and opinions of their respective authors and are not the views or opinions of the IRA. The IRA disclaims of any harm or loss caused due to the published content to any party. 


\begin{abstract}
The importance of communication skills and its research is recognized throughout the world. Self learning is one such option to improve communication skills. The goal of the present study is discussing the significance of self learning and some of its tools in developing communication skills of technical students. At present self-learning is limited to which activities and skills and where and how can we extend and promote self learning in technical colleges is mentioned. These self learning tools include: reading, note taking, note making, conversation, watching educational videos, video recording, MALL, $C A L L$, and socialization. The relevant literature support and researcher's personal experience in different technical colleges is added.
\end{abstract}

Key words: Self-learning, distance learning, CALL, communication skills

\title{
1. Introduction
}

Communication skills are required in most occupations. Employers identify communication as one of the basic competencies every graduate should have, asserting that the ability to communicate is valuable for obtaining employment and maintaining successful job performance. The communication skills essential in the work place include basic oral and writing skills, and the ability to communicate in work groups and teams with persons of diverse background, and when engaged in problem solving and conflict management (Morreale et al., 2000). Technical colleges have recognized the importance of communication skills. Several colleges have taken steps to resolve the gap between learners and industry. In this regard, a lot of research has been done. The continuous updated and innovatory research is always necessary.

The goal of teaching-learning is to have suitable method which gives maximum output with minimum investment. Research to improve teaching-learning is a continuous process. In this process, many innovatory methods are introduced. As Agabatogun (2014) also opines different pedagogical strategies have varying degrees of success.

Self learning is one such method. Self-learning is gaining prominence in every field of academics because of its range of benefits. Some of these most popular benefits include: learning by oneself at one's own pace, place, and time.

Self learning is "learning done by oneself without a teacher or instructor" (your dictionary, 2016).

Self learning can also be termed as self taught, self study, self-directed, lifelong learning, informal learning, distance learning, personal learning, etc.

Webster (2016) defines self taught as: "educated by your own efforts (such as by reading books) rather than by a teacher", "learned by your own efforts rather than at school".

Oxford learners' dictionary (2016) defines self study as "the activity of learning about something without a teacher to help you" and self-directed learning is "under one's own control".

There are several examples of self study in the form of online courses. For example: a semester-long online course of IIT, Bombay (IIT, Bombay, 2016).

At present, few guidelines exist on how college instructors should incorporate self-regulated strategies (Dabbagh, 2014). 


\section{The objectives of this paper are to}

- Discuss the significance of self learning in developing communication skills of technical students.

- Mention some of the tools or opportunities for self learning and how and where can we apply these tools

\section{The study area}

The study area is an autonomous engineering college under JNTUH, where communication skills taught for B.Tech. first and third years.

\subsection{The learners}

Learners are at their tertiary level. Most of them belong to English medium during their tenth and plus two standard. At present, they are in B.Tech. first year and B.Tech. third year. B.Tech. first year students have communication skills for two semesters about 60 hours with CALL and ICS labs. With this background, they enter to B.Tech. third year. They participate in advanced communication skills lab, for a semester, about 30 hours.

\section{Self learning at present}

At present, communication skills are practiced in the following ways:

Listening skill is practiced through CDs, and interactive software. It helps in learning pronunciation, sentence structure, etc. Students are required to expose to authentic material, wherever and whenever necessary. At present apart from some authentic speeches, most of the software material is prepared. However good the material is, it is not equivalent to authentic material.

Speaking skill is limited to communication skills lab with interactive software

The need for using authentic spoken tasks is also recommended by Vanitha and Mamata, 2016. It is necessary to set up real-life related tasks. When the tasks are linked to the real life, a strong learning atmosphere would be created. This makes the learning process faster and easier.

Reading skill is limited to texts of different subjects and English and mostly notes given by their teachers in different subjects.

Writing skill is limited to writing of assignments, examinations, creative writing of certain activities such as, dialogue writing, report writing, letter writing, etc.

Apart from giving practice in writing, some of the self-corrected exercises are to be given.

Building of vocabulary is through learners' software and books and dictionary.

Grammar exercises are practiced through the software and books.

Socialisation is through face book, mobile phones, apps, etc. Learners may share notes, converse, etc.

Communicative language teaching is based on real-life situations that require communication. In this mode, students will have the opportunity of communicating with each other in the target language (Kayi, 2006). Though at present communication skills are practiced in a number of ways, innovatory methods are always necessary to suit the needs of changing needs of students. Use of authentic materials, which 
are based on real-life situations, provides exposure to contextualised material. This enables learners to learn the language appropriately. Thus, language errors are minimized.

\section{Various ways to promote self learning}

In the following paragraphs various ways to promote self learning are mentioned. They include: reading, note taking, note making, conversation, watching educational videos, video recording, MALL, CALL, and socialisation.

\subsection{Reading}

Read books and articles on a topic of study, or interest. Encouraging a learner to read is a highly effective way to increase understanding of new concepts. Take a trip to the library together to self study (Oxford learning 2015). For example, students are asked to read a joke, where some sentences or words are removed. Students need to replace the words or sentences, while reading aloud. The same can be applied to the writing skills as well.

\subsection{Notes taking and notes making}

During the lecture hours of different subjects a learner should be encouraged to take notes, and organize it for future reference. At present, learners are habituated to readymade notes. Thus, learners need practice of this skill.

Activities such as, locating a particular technical content of their choice from a bigger text (scanning skill) and making concise notes can be implemented.

\subsection{Conversation}

Have a conversation with a learner about what is being learned at college, and what topics your learner is interested in. This will encourage students to strive to learn more, so they can keep teaching you what they know. Additionally, the practice of teaching is known as one of the top ways to work towards grasping a concept (Oxford learning 2015).

During the revision of syllabus, student can be asked about the topics of his/ her interest. They may try to converse and explain the topics in details. It can be extended to writing activity as well.

\subsection{Watching educational videos}

Watch educational videos to keep learners actively engaged in a concept. There are many tutorial videos that are intended for teaching people new skills, or educational shows aimed at complementing what students learn in school. Whether a learner is trying to learn another language, or figuring out how to conduct a science experiment, they can greatly benefit from the audio and visual walkthrough (Oxford learning 2015).

After watching video films, students can write a review and also discuss in the class. For example, by watching demonstration of describing a product one can learn how to describe and demonstrate a product. This activity can be applied to speaking and writing skills.

\subsection{Video recording}

Video recording of PPTs, mock interviews, etc. for self evaluation - Students should be given evaluation sheets with parameters for evaluation. Evaluation sheets may contain parameters such as: Vocabulary (number of words), reading(speed / comprehension), writing (accuracy/appropriacy), listening(note 
taking/ comprehension), body language, confidence, decision making, work with others, team contribution, attitude (acceptance/friendly), etc.

Researcher has used the evaluation sheets for B.Tech. third year students for evaluating role plays, PPTs, interview skills, group discussions, etc. which work remarkably. Apart from self evaluation, peer evaluation can also be done, to compare and improve the students' performance.

\subsection{MALL (Mobile Assisted Language Learning) (Jarvis and Achilleos, 2013)}

Educational games are a child and parent favourite when it comes to ways to study at home. There are many apps that you can access through your phone that promote learning in math, English, and a variety of other courses. Or put the phone down and get hold of board games and card games that promote strategy and logic. Encourage your learner to associate learning with fun (Oxford learning 2015). Students are already using mobile phones for various purposes. It can be extended to language games as well. This avoids monotony of way of learning. In MALL, language learning happens unselfconsciously.

\subsection{CALL (Computer Assisted Language Learning)}

Computer Assisted Language Learning (CALL) is often perceived, somewhat narrowly, as an approach to language teaching and learning in which the computer is used as an aid to the presentation, reinforcement and assessment of material to be learned, usually including a substantial interactive element (Jarvis and Achilleos, 2013). Apart from the traditional usage of computers for language learning, CALL is also helpful for self evaluation, practicing exercises, for revising grammar through grammar games which are highly interactive, motivating and which also grab the attention of the students easily.

Initially, CALL has been used for a few basic mechanical "drill and kill" software programs. CALL has grown to include online blogs, use of apps, virtual learning environments, computer-mediatecommunication, among others (Jarvis and Achilleos, 2013). Use of apps is a common practice for several academic purposes. For example, "Learn English Grammar is a top interactive grammar practice app designed to help improve English grammar accuracy. The app offers 1000s of questions to help practice and reinforce your English grammar skills".

\subsubsection{Multimedia CALL}

A feature of many multimedia CALL programs is the role-play activity, in which the learner can record his/her own voice and play it back as part of a continuous dialogue with a native speaker. Other multimedia programs make use of Automatic Speech Recognition (ASR) software to diagnose learners' errors, e.g. Tell Me More Pro by Auralog: http://www.auralog.com/english.html (Davies, 2016). Though students participate in various varieties of speaking activities- this may not meet the demands of all learners. Some students need more practice with certain activities. Those students can get benefited with multimedia CALL. Apart from this, students who need practice to improve their communication skills can listen to native speakers' voice and also record their own pronunciation to compare and contrast with the native speakers' pronunciation.

\subsubsection{Web-based CALL}

Adopting hybrid approaches to CALL, integrating CD-ROMs and the Web and running audio conferencing and video conferencing in conjunction with Web activities is the need of time. The Web Enhanced Language Learning (WELL) project, website provides access to high-quality Web resources in a number of different languages, selected and described by subject experts, plus information and examples on how to use them for teaching and learning: http://www.well.ac.uk/ (Davies, 2016). Different 
websites have online exercises, games, ready reference dictionaries - which enable learners move forward quickly in their self learning process.

Students can also participate in online conferences, sample tests, online tests, etc. Students can also have a meeting with subject experts within the country and outside.

\subsection{Socialization}

The integration of social software into learning design can make a qualitative difference to giving students a sense of ownership and control over their own learning and career planning. However, universities and colleges generally rely on conservative, established course management systems and virtual learning environments that do not fully capitalise on the potential of social media that enable participation in global learning networks, collaboration and social networking. Recently, the personal learning environment (PLE) has emerged as a concept associated with the adoption of a raft of Web 2.0 tools that serves to integrate essential learning outcomes such as lifelong learning, informal learning and self directed learning (McLoughlin and Lee, 2010). It is necessary to have updated information regarding the latest relevant tools, which makes the learning process more comfortable and particularly self learning.

The learning experiences that are made possible by social software tools are active, process based, anchored in and driven by learners' interests, and therefore have the potential to cultivate, self regulated, independent learning (McLoughlin and Lee, 2010). Students are not forced to any external obstructions, thus, they feel independence in using social software tools. Students work on their own like any other social activities.

Work through practice questions to reinforce skills that are learned at college while studying at home. Help hold your learner's attention while working through the practice questions by incorporating games, rewards, and challenges. This will help them view the material in a new way, and reinforce what is learned in the classroom (Oxford learning 2015). Through social websites students are able to communicate whole heartedly. Students are less conservative, more interactive and thus enabling students to express freely - which also minimizes errors.

\section{Discussion}

Many students study at home to supplement their class-based learning. However, self study can also be used to master a new skill or learn an entirely new concept - like a language or an instrument. The benefits you can gain from self study are endless and are completely determined by yours and your learner's goals (Oxford learning, 2015). The advantages of self study are numerous. Teachers, who are teaching in technical colleges, can possibly make use of the range of advantages, which are mentioned in this paper, and some more.

Self studying, which involves studying without direct supervision or attendance in a classroom, is a valuable way to learn, and is quickly growing in popularity among parents and students. By complementing formal education with home study, students can see a drastic improvement to grades, material understanding, and confidence (Oxford learning, 2015). Apart from learning in classrooms, self study is necessary for revising in a different ways, gaining confidence and improving the performance.

Personal learning models allow learners to make decisions about how to choose tools and configure the learning environment to best suit their learning goals and needs for networking, knowledge construction, social interaction and collaboration. In addition, both challenge traditional pedagogies where the teacher 
is the celebrated expert, dispensing knowledge and prescribing learning resources and activities (McLoughlin and Lee, 2010). A learner has the freedom to choose a preferred personal learning model, which are available in the form of online material.

Self-assessment has been shown to help students develop meta-cognitive skills that can be used in all aspects of higher education, and it has been shown to improve student achievement in a range of different academic areas (Ritchie, 2016). In researcher's personal experience, evaluation sheets are already used for B. Tech. third year students for role plays, PPTs, interview skills, group discussions, and the other activities.

The communication discipline is an essential component of the educational enterprise- from preschool to adult education. The field is particularly important in the arena of higher education (Morreale et al., 2000). During their higher education, learners need to communicate within and outside their institute for gathering and sharing research ideas and for their professional growth.

Given the importance of the ability to communicate competently, the communication discipline should be viewed as central on college campuses (Morreale et al., 2000). The importance of communication skills has been recognized in many Indian universities. But, some more upward movement in this regard is mandatory to meet the industry demands, particularly for technical students.

The global learning landscape of the twenty-first century is being transformed and shaped by the uptake of digital communication tools and ubiquitous networked applications, along with the changing characteristics, needs and demands of students (McLoughlin and Lee, 2010). Though communication skills are in continuous demand and research is moving forward, continuous upgradation of innovatory research ideas to meet the changing demands is the need of the hour.

\section{Conclusion}

Successful communication contains four competencies namely- Linguistic, Socio-linguistic, Strategic and Discourse (Communication Competence Model, Bachman and Palmer, 2010).

Research findings in recent years provide compelling evidence of the importance of encouraging student control over the learning process as a whole (Loughlin and Lee, 2010). Students, particularly, the present generation students need a lot of freedom in every field of academics. This particular approach helps learners to grow beyond their academic barriers.

Teacher's role is not limited to information transfer, but to serve as a facilitator for learning. This involves creating and managing meaningful learning experiences and stimulating students' thinking through real world problems. At present, training for college teachers to teach communication skills is provided by universities and companies. But, only some college teachers are trained.

The results of Morreale et al., 2000 reported clearly indicate that communication education develops the whole person, improves the work of education, advances the interests of society, and bridges cultural differences, and advances careers and the work of business. Thus, it is essential that communication curricula should be led and taught by specialists trained in the discipline and in departments that are dedicated to the study of communication.

A self regulated learner is able to execute learning activities that lead to knowledge creation, comprehension and by using processes such as monitoring, reflection, testing, questioning and self evaluation. The quest for learning to be 'student centred', self directed and self regulated has long been a pursuit of educators (McLoughlin and Lee, 2010). Thus, learner independence in knowing the facts, researching, regulating, monitoring, and evaluating leads to learner's success in their chosen field of study. 


\section{References}

1. Agbatogun, A. O., 2014. Developing Learners' Second Language Communicative Competence through Active Learning: Clickers or Communicative Approach? Educational Technology \& Society, 17(2), 257-269.

2. Bachman, L. F., \& Palmer, A. S. (2010). Language assessment in practice. Oxford: Oxford University Press.

3. Dabbagh, N. \& Kitsantas, A., 2004. Supporting Self-Regulation in Student-Centered Web-Based Learning Environments. International Journal on E-Learning, 3(1), 40-47. Norfolk, VA: Association for the Advancement of Computing in Education (AACE).

4. Davies Graham, 2016: CALL (computer assisted language learning), Center for languages, linguistics and area studies, https://www.llas.ac.uk/resources/gpg/61\#toc_4, retrieved on 28.06.2016

5. IIT,Bombay,2016: https://www.iitbombayx.in/courses/IITBombayX/HS791xS16/2016_T1/about, Retrieved on 20.09.2016

6. Jarvis Huw and Achilleos Marianna, March 2013: From Computer Assisted Language Learning (CALL) to Mobile Assisted Language Use (MALU), Volume 16, Number 4, http://www.teslej.org/wordpress/issues/volume16/ej64/ej64a2/

7. Kayi Hayriye, 2006: Teaching Speaking: Activities to Promote Speaking in a Second Language, The Internet TESL Journal, Vol. XII, No. 11, November 2006, http://iteslj.org/

8. McLoughlin Catherine and Lee J. W. Mark, 2010: Personalised and self regulated learning in the Web 2.0 era: International exemplars of innovative pedagogy using social software, Australasian Journal of Educational Technology, 2010, 26(1)

9. Merriam Webster, 2016: http://www.merriam-webster.com/dictionary/self\%E2\%80\%93taught, retrieved on 25.09. 2016

10. Morreale P S, Osborn M M, Pearson C, 2000: Why Communication is Important: A Rationale for the Centrality of the Study of Communication, Journal of the Association for Communication Administration 29(2000), 1-25

11. Oxford learning, 2016: http://www.oxfordlearnersdictionaries.com/definition/english/self-study_2 , Retrieved on 20.09.2016

12. Oxford learning, 2015: Best Methods of Self Study for Students: Enrichment, High School, Homework, Middle school, https://www.oxfordlearning.com/best-methods-of-self-study-forstudents/, Retrieved on 20.09.2016

13. Ritchie M Sian 2016: Self-assessment of video-recorded presentations: Does it improve skills? Active Learning in Higher Education 2015, Vol. 16(1) 3-10 http://alh.sagepub.com/content/early/2016/06/21/1469787416654807.abstract

14. Vanitha Chopra and Mamata Saluja, 2016: Strategies for assessing spoken skills, Teaching for success, online conference, 5-9OCT, 2016, British Council

15. Your dictionary, 2016: http://www.yourdictionary.com/self-learning, Retrieved on 20.09.2016 